\title{
Upper limb Gangrene from Axillary Artery Ligation
}

\section{JCR}

\section{Kadir Dotun $M^{1}$, Jimoh OR ${ }^{2}$, Kadir RE ${ }^{3}$}

Orthopedic Unit, Department of Surgery, 'General Hospital, Ilorin and ${ }^{2}$ Sobi Specialist Hospital, Sobi, Kwara State; ${ }^{3}$ Department of Human Anatomy, University of Ilorin, Ilorin, Kwara State, Nigeria.

\section{Abstract:}

Gangrene involving the whole upper limb is generally uncommon. When seen, it usually affects parts of the upper limb and is usually as a result of mismanagement of fractures by traditional bone setters (TBS). We present the case of a 2 year old girl with gangrene of the upper limb as a result of inadvertent ligation of the axillary vessels. Lack of recognition of the error and delayed presentation to a specialist center contributed to irreversible damage to the limb. Prompt resuscitation, excision of gangrenous limb and postoperative care were indispensable in the excellent outcome achieved.

Key words: Bone, Fractures, Gangrene, Ligation, Upper Extremity.

\section{Introduction}

Upper limb gangrene commonly occurs as a result of fracture mismanagement by traditional bone setters (TBS) or in humeral head or neck fractures [1-3]. Less common causes include vascular cannulation for dialysis, arteriography, thrombolysis, arthroscopy of the shoulder joint, following intravenous injection of drugs and infections such as gas gangrene [46]. Rarely it is found as a consequence of trauma and one study found that serious distal ischemia is uncommon in upper limb injuries resulting from trauma [7]. Therefore we present this case report of upper limb gangrene in a child following suture ligation of the axillary artery.

\section{Case Report}

A 2 year old female child presented with four day history of injury to the right axilla following a pedestrian road traffic accident. She sustained lacerations to the inner arm and axilla, abrasions to the scalp, back and chest wall with associated pain and bleeding from injury sites. She was taken to a private hospital where the medical personnel on duty was said to have brought the bleeding under control by ligating the vessels and suturing the skin. The mother says the patient was crying throughout the procedure. By the second day, the mother noticed the right upper limb (RUL) was cold and turning dark. A decision to move the patient to our center more than $500 \mathrm{~km}$ away was taken by the parents when there was no improvement in the state of the limb.

An acutely ill looking, pale, febrile $\left(38.6^{\circ} \mathrm{C}\right)$, dehydrated, anicteric and toxic looking child

\section{Corresponding Author: Dr. Kadir Dotun M}

Email: dotunk@yahoo.com

Received: April 15, 2016 | Accepted: July 21, 2016 | Published Online: September 5, 2016

This is an Open Access article distributed under the terms of the Creative Commons Attribution License (creativecommons.org/licenses/by/3.0)

Conflict of interest: None declared | Source of funding: Nil | DOl: http://dx.doi.org/10.17659/01.2016.0101 
presented to us on the fourth day following the injury with a Glasgow coma score (GCS) of 8. Her vital signs were pulse rate: $124 / \mathrm{min}$, respiratory rate: 40 cycles/min. The RUL was black, cold, gangrenous and edematous from the finger tips to the shoulder and lateral chest wall [Fig.1a,1b]. There were no peripheral pulsations, sensations or movement noticed. The sutured axillary wound had broken down and suture material could be seen. There was foul smelling purulent discharge oozing from the axilla. Abrasions were also present on the trunk anteriorly and posteriorly. No injuries or abnormalities were found on other parts of the body. An impression of gangrene of the right upper limb from axillary artery ligation in a patient with septic shock was made.

Resuscitation was commenced with intravenous fluids and later blood transfusion of packed cells@20ml/kg for packed cell volume (PCV) of $22 \%$. Tetanus prophylaxes, parenteral broad spectrum antibiotics were started empirically. She was tepid sponged and administered paracetamol to control fever. Urethral catheterization to monitor urinary output and thus tissue perfusion was carried out. Wound swab microscopy, culture and sensitivity produced a moderate growth of Staphylococcus aureus. Her parents were counseled on the diagnosis and consent for examination under anesthesia, disarticulation at the shoulder joint and wound debridement was obtained. She had surgery within 48 hours on admission as a result of financial constraints, resuscitation time and hospital logistics. At this time GCS was 15.

Under general anesthesia, the axilla was examined in detail and it was found that the axillary vessels had been ligated in a bunch with chromic sutures which were liquefying [Fig.2]. The subclavian vessels were exposed, ligated and divided following excision of the lateral $1 / 3$ of the right clavicle. Disarticulation proceeded through the demarcated skin via blunt dissection.

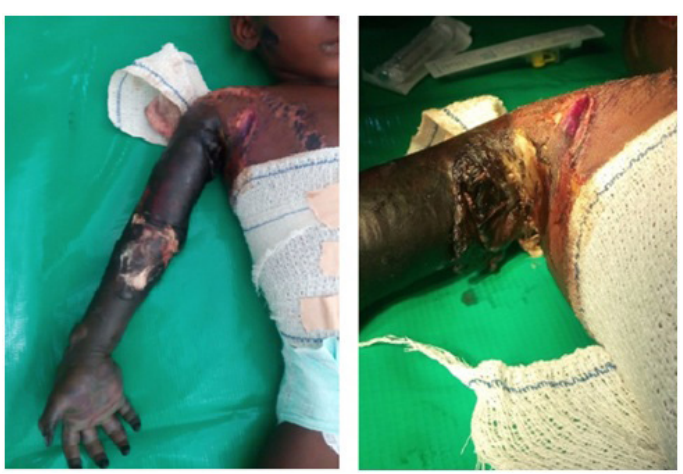

Fig.1: Gangrenous limb on presentation.

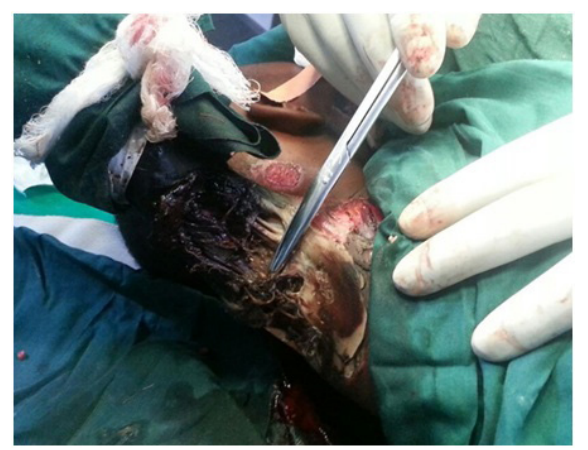

Fig.2: Intra-operative ligated vessels in a bunch of chromic sutures.

The deltoid muscle was then debrided of necrotic tissue. The joint capsule was exposed, incised and disarticulation was completed by sharp dissection. The remnant of the capsule was then sutured over the exposed glenoid cavity and skin flaps created for secondary closure at a later date [Fig.3]. The wound was irrigated with saline and dressed. Postoperative condition was satisfactory.

The wound was not closed to allow for chemical debridement with saline, povidone iodine and honey as the desloughing agent in the ward. Post-operative PCV was $30 \%$. The wound improved significantly over the next two weeks and secondary closure was planned. However, the skin flaps were noticed to have contracted significantly [Fig.4] therefore split thickness skin grafting of the 
residual ulcer was planned. This procedure was also cancelled because patient developed an upper respiratory tract infection. She was discharged at 2 weeks post-operative to continue medication and dressing on outpatient basis. The wound has since contracted and healed.

\section{Discussion}

The subclavian artery continues as the axillary artery at the lateral boarder of the first rib and ends at the inferior border of the teres major muscle and is divided into 3 parts [8]. It disappears completely with the arm fully adducted and vulnerable to injury when abducted. It is easily palpated against the humerus just below the axilla. The first and second parts are located higher in the axilla and protected from injury. The anastomotic network surrounding the scapular provides an alternate path for collateral circulation through the dorsal scapular artery and suprascapular artery [9]. Ligation or injury to the third part of the artery between the subscapular artery and profundii brachi artery will cut of blood supply to the arm and lead to gangrene because the collateral circulation at this level is inadequate. In emergency situations involving bleeding from a major vessel, attempts should be made to control bleeding by direct pressure initially followed by clipping the artery in preparation for repair or ligation if the vessel has collateral supply to distal structures. Once vascular injury occurs, the clock starts ticking as irreversible damage occurs within 6 hours. The consequences of this injury include blood loss, progressive ischemia, compartment syndrome and tissue necrosis. Controlling bleeding in a young child who has pain, scared of needles and health personnel can be difficult and almost impossible without sedation or anesthesia.

The patient presented to a privately owned clinic/hospital where specialist personnel is usually lacking. It was difficult to assess the type of facility the patient was taken to due to distance. Most of

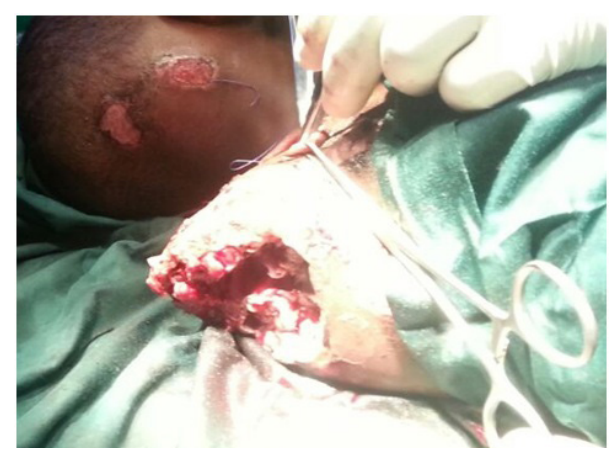

Fig.3: Intra-operative post-disarticulation with flaps.

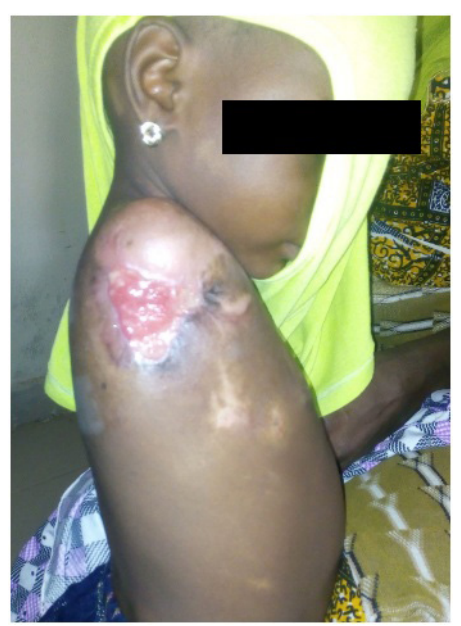

Fig.4: Two weeks post-disarticulation with residual ulcer.

these facilities are owned by non-specialist doctors or non-doctors and manned by inexperienced doctors, male nurses or community health extension workers (CHEW) as the case may be to keep overhead costs down and are usually underfunded [10]. This patient would have benefited from the services of a vascular surgeon and an anesthetist. We believe that the following factors might have contributed to gangrene of the limb: the closeness of the vessels to the skin with the limb abducted during repair of the laceration, the tiny structures of the patient, lack of proper anesthesia and relaxation to allow for identification and protection 
of the vessels, inexperience of the caregiver and lack of collateral circulation to the distal extremity. On examination of the axilla [Fig.2], the laceration was directly over the ligated vessels which were tied up in one bunch with chromic sutures. This we believe was a wrong choice of suture material as it was also used to close the skin. Due to the location of the injury and the age of the patient, it would have been appropriate to anesthetize the patient. Because gangrene was already established on presentation, assessment of classic signs of vascular injury and associated brachial plexus injury were deemed unnecessary. Our approach was to tie the subclavian vessels via a clean wound under the clavicle and disarticulate from the shoulder joint. This left a void which was filled with remnants of the capsule and deltoid muscle. Secondary suturing was planned but was canceled due to contraction of the skin flaps that were left. We also planned to graft the residual wound with split thickness skin grafts but this was not possible because the patient developed an upper respiratory tract infection. She was discharged four weeks after admission to the follow up clinic where the wound has completely healed [Fig.5]. William reported of a case of gangrene (in evolution) of the upper limb in which inflammation to the base of the neck as a result of a hematoma annulled amputation at the shoulder. He decided to wait for a demarcation line before proceeding to surgery. He however lost the patient [ 11 1]. In contrast our patient presented with a demarcation line and gangrene was established.

It is worth noting that lacerations to vessel should be managed by preserving collateral vessels and use of vascular conduits (autologous or synthetic) over end-to-end anastomosis [12]. Failed revascularization may also require limb amputation.

\section{Conclusion}

Major vascular injuries are emergencies and should be managed by competent personnel. First-

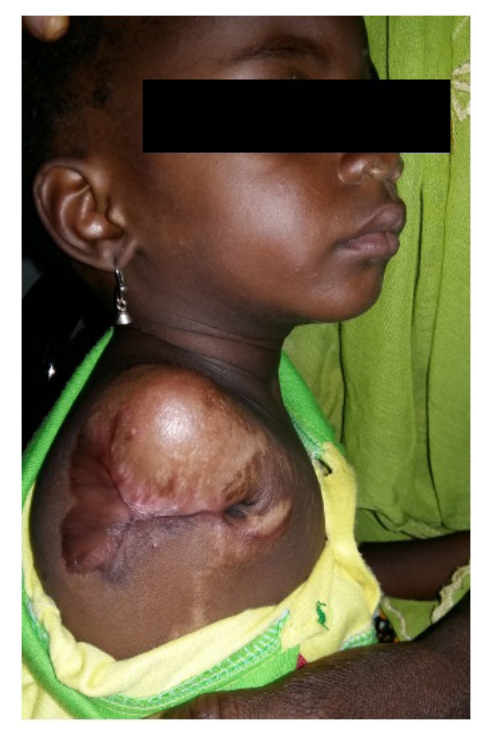

Fig.5: Six weeks post-disarticulation with healed ulcer.

aid and prompt referral to specialist centers for appropriate management will help in reducing morbidity and limb loss and avoidable mortality. Training and retraining of medical personnel via continued medical education and postgraduate training cannot be over emphasized.

\section{References}

1. Garba ES, Deshi PJ, Ihejirika KE. The role of traditional bone setters in limb amputations in Zaria. Nigerian Journal of Surgical Research. 1999;1:21-24.

2. Yakubu A, Muhammad I, Mabogunje O. Limb amputation in children in Zaria, Nigeria. Ann Trop Paediatr. 1995; 15:163-165.

3. Onuminya JE, Onabowale BO, Obekpa $\mathrm{PO}$, Ihezue $\mathrm{CH}$. Traditional bone setter's gangrene. International Orthopaedics (SICOT). 1999;23:111-112.

4. Cawich SO, Mohammed E, Mencia M, Naraynsingh V. Upper limb ischemic gangrene as a complication of hemodialysis access. Case Rep Vasc Med. 2015;2015:815616. 
5. Robin M Seagger, Kitson J. A rare combination of an axillary artery and brachial plexus injury due to proximal humeral fracture. Int J Surg. 2009;3:71-73.

6. Hajong R. Upper limb gangrene following intramuscular diclofenac: a rare side effect. J Surg Case Rep. 2:2013.

7. Robbs JV, Baker LW. Major arterial trauma: review of experience with 267 injuries. $\mathrm{Br} J$ Surg. 1978;65:532-538.

8. Wikipedia.com. Axillaty artery. Wikipedia, The Free Encyclopedia, 2015. Available from: https://en.wikipedia.org/wiki/Axillary_artery.
Accessed on April 15, 2016.

9. Moore KL, Dalley AF, Anne MR. Agur. Moore Clinically Oriented Anatomy. Lippincott Williams \& Wilkins, 2014.

10. Afolabi JK. Overview of the Global Trend in Private Medical Practice. Savannah Journal of Medical Research and Practice. 2013;2:1-11.

11. Willian RE Smart. Injury to the axillary artery causing gangrene of the upper extremity. $\mathrm{Br}$ Med J. $1871 ; 2: 342$.

12. Graham JM, Mattox KL, Feliciano DV, DeBakey ME. Vascular injuries of the axilla. Ann Surg. 1982;195:232-238. 